\title{
Langmuir
}

pubs.acs.org/Langmuir

(C) 2010 American Chemical Society

\section{Adsorption, Desorption, and Surface-Promoted Hydrolysis of Glucose-1-Phosphate in Aqueous Goethite $(\alpha-\mathrm{FeOOH})$ Suspensions}

\author{
Rickard Olsson, ${ }^{\dagger}$ Reiner Giesler, ${ }^{\star}$ John S. Loring, ${ }^{\dagger} §$ and Per Persson $*, \dagger$ \\ ${ }^{\dagger}$ Department of Chemistry, and ${ }^{*}$ Climate Impacts Research Centre, Department of Ecology and Environmental \\ Science, Umeå University, SE-901 87 Umeå, Sweden, and ${ }^{\S}$ Pacific Northwest National Laboratory, \\ Richland, Washington 99352, United States
}

Received June 29, 2010. Revised Manuscript Received September 8, 2010

\begin{abstract}
Adsorption, desorption, and precipitation reactions at environmental interfaces govern the fate of phosphorus in terrestrial and aquatic environments. Typically, a substantial part of the total pool of phosphorus consists of organophosphate, and in this study we have focused on the interactions between glucose-1-phosphate (G1P) and goethite $(\alpha-\mathrm{FeOOH})$ particles. The adsorption and surface-promoted hydrolysis reactions have been studied at room temperature as a function of $\mathrm{pH}$, time, and total concentration of G1P by means of quantitative batch experiments in combination with infrared spectroscopy. A novel simultaneous infrared and potentiometric titration (SIPT) technique has also been used to study the rates and mechanisms of desorption of the surface complexes. The results have shown that G1P adsorption occurs over a wide $\mathrm{pH}$ interval and at $\mathrm{pH}$ values above the isoelectric point of goethite $\left(\right.$ IEP $\left._{\text {goethite }}=9.4\right)$, indicating a comparatively strong interaction with the particle surfaces. As evidenced by IR spectroscopy, G1P formed $\mathrm{pH}$-dependent surface complexes on goethite, and investigations of both adsorption and desorption processes were consistent with a model including three types of surface complexes. These complexes interact monodentately with surface Fe but differ in hydrogen bonding interactions via the auxiliary oxygens of the phosphate group. The apparent desorption rates were shown to be influenced by reaction pathways that include interconversion of surface species, which highlights the difficulty in determining the intrinsic desorption rates of individual surface complexes. Desorption results have also indicated that the molecular structures of surface complexes and the surface charge are two important determinants of G1P desorption rates. Finally, this study has shown that surface-promoted hydrolysis of G1P by goethite is base-catalyzed but that the extent of hydrolysis was small.
\end{abstract}

\section{Introduction}

Phosphorus occurs in nature mostly as inorganic phosphates or as organophosphates, where the phosphate group is incorporated into organic molecules via ester bonds. Hence, the biogeochemistry of phosphorus is controlled almost exclusively by the chemical properties of the phosphate group. A unique property of phosphates compared to most other essential nutrients is the unusually large reactivity toward solid particles in the natural aquatic environment, especially those containing $\mathrm{Al}, \mathrm{Mn}$, and Fe. Thus, adsorption, desorption, and precipitation reactions at environmental interfaces govern the fate of phosphorus and greatly influence biomass production in ecosystems.

Organophosphates constitute a substantial part of the total phosphorus in soils, ${ }^{1}$ and they are important for plant and microbial phosphorus acquisition. ${ }^{2,3}$ Accordingly, to understand problems associated with both nutrient deficiencies caused by limited access of phosphorus as well as excess of phosphorus leading to eutrophication, the role of organophosphates needs to be considered. Furthermore, phosphates are non-renewable natural resources, and the current use involves practically no form of recovery. ${ }^{4}$ Fertilizers make up approximately $75 \%$ of the anthropogenic phosphorus, and most of this fraction ends up in soils. ${ }^{4}$ Due to biological activity, part of the phosphorus introduced via

*To whom correspondence should be addressed. E-mail: per.persson@ chem.umu.se. Telephone: +4690786 5573. Fax: +46 907867655.

(1) Bourke, D.; Dowding, P.; Tunney, H.; O'Brien, J. E.; Jeffrey, D. W. Proc. R. Ir. Acad. 2008, 108B, 17.

(2) Attiwill, P. M.; Adams, M. A. New Phytol. 1993, 124, 561.

(3) George, T. S.; Gregory, P. J.; Robinson, J. S.; Buresh, R. J.; Jama, B. Plant Soil 2002, 246, 53.

(4) Villalba, G.; Liu, Y.; Schroder, H.; Ayres, R. U. J. Ind. Ecol. 2008, 12, 557. fertilization will be transformed to organophosphates, and hence, an enhanced plant acquisition of this fraction would promote a more efficient and sustainable use and potentially also reduce losses of phosphorus.

An important and common group of organophosphates are the phosphorylated sugars that encompass molecules with various degrees of phosphorylation including the biochemically important molecules glucose-1-phosphate and glucose-6-phosphate. Such sugar monoesters have been indicated to occur at significant concentrations in soils. ${ }^{5,6}$ An important intracellular function of these molecules is to keep glucose within the cell as phosphorylation retards transfer across the cell membrane. With respect to the reverse process and phosphorus uptake, it follows that these molecular structures may not be directly assimilated by plants and microorganisms but require prehydrolysis of the phosphate ester bond in order to produce bioavailable phosphate. ${ }^{7,8}$ In accordance with inorganic phosphates, the organic analogues adsorb strongly to environmental particles. ${ }^{9-12}$ Thus, hydrolysis most likely occurs at or close to interfaces. Adsorption of organophosphates has been suggested to block enzymatic hydrolysis; however,

(5) Pant, H. K.; Warman, P. R.; Nowak, J. Commun. Soil Sci. Plant Anal. 1999, 30,757 .

(6) Espinosa, M.; Turner, B. L.; Haygarth, P. M. J. Environ. Qual. 1999, 28 , 1497.

(7) Paytan, A.; McLaughlin, K. Chem. Rev. 2007, 107, 563.

(8) Cotner, J. B.; Wetzel, R. G. Limnol. Oceanogr. 1992, 37, 232

(9) Celi, L.; Lamacchia, S.; Marsan, F. A.; Barberis, E. Soil Sci. 1999, 164, 574.

(10) Celi, L.; Presta, M.; Ajmore-Marsan, F.; Barberis, E. Soil Sci. Soc. Am. J. 2001, 65, 753 .

(11) Martin, M.; Celi, L.; Barberis, E. Soil Sci. 2004, 169, 115 .

(12) Giaveno, C.; Celi, L.; Richardson, A. E.; Simpson, R. J.; Barberis, E. Soil Biol. Biochem. 2010, 42, 491 . 
recent studies indicate that some molecular structures are susceptible to enzymes also in an adsorbed state. For instance, bioassays using glucose phosphate and orthophosphate indicate that plants and microorganisms utilize these substrates equally efficient. ${ }^{13,14}$ This may be the result of dephosphorylation due to phosphatase activity as has been suggested by Fransson and Jones ${ }^{15}$ or abiotic hydrolysis of glucose phosphate facilitated by mineral surface interactions. The latter has been shown for iron and manganese oxides that facilitated the hydrolysis of para-nitrophenyl phosphate $^{16,17}$ and may also occur for other organophosphates. In any case and from these examples only, it is clear that in order to grasp the concept of phosphorus bioavailability at a fundamental level we need to have an understanding of reactions of organophosphates at surfaces of environmental particles.

At present, there are only a few studies on the molecular-level aspects of these reactions involving phosphorylated sugars, and these studies focus primarily on the adsorption process. ${ }^{10,18-20} \mathrm{In}$ the present study, we broaden the scope and focus on adsorption, desorption, and surface-promoted hydrolysis of glucose-1-phosphate (G1P) on $\alpha-\mathrm{FeOOH}$ (goethite), which is a common $\mathrm{Fe}$ mineral in soils and known to strongly adsorb phosphates and phosphonates. In particular, we address questions concerning structures of G1P surface complexes as well as their relative rates of desorption and their sensitivity toward hydrolysis. These are factors that ultimately control the availability of G1P. To meet the research objectives, we combine results from quantitative batch experiments where adsorption and hydrolysis are monitored as a function of time with infrared spectroscopic studies on the molecular structures of the surface complexes. A novel simultaneous infrared and potentiometric titration (SIPT) technique is also used to study the rates of desorption of the surface complexes. ${ }^{21}$

\section{Experimental Section}

2.1. Chemicals, Solutions, and Suspensions. Deionized (Milli-Q Plus) and boiled water was used to prepare all solutions and goethite suspensions. $\mathrm{NaCl}$ (Merck, p.a.) dried at $180^{\circ} \mathrm{C}$ was used to prepare a background electrolyte concentration of $50 \mathrm{mM}$ $\mathrm{Na}(\mathrm{Cl})$. pH adjustments were made with $\mathrm{NaOH}(50 \mathrm{mM})$ and $\mathrm{HCl}(50 \mathrm{mM})$. A G1P stock solution was prepared by dissolving a weighed amount of G7000 (Sigma-Aldrich, 98\%), and the concentration was verified by a potentiometric titration. The G1P and the $50 \mathrm{mM} \mathrm{Na}(\mathrm{Cl})$ solutions were sterilized by filtration through a $0.2 \mu \mathrm{m}$ Sarstedt filter (Filtropur S 0.2). The G1P solution was kept frozen until use. A glucose recovery experiment was carried out in order to determine the extent of possible microbial degradation during the experiments. A volume of glucose stock solution was transferred to a $15 \mathrm{~mL}$ polypropylene centrifuge tube. After dilution with ionic medium and $\mathrm{pH}$ adjustments, the glucose concentration was $50 \mu \mathrm{M}$. The samples were protected from light by wrapping the centrifuge tubes in aluminum foil, and after equilibrating at $25{ }^{\circ} \mathrm{C}$ on an end-over-end rotator for $48 \mathrm{~h}$ the $\mathrm{pH}$ of each sample was measured. The samples were sterilized by filtration through a $0.2 \mu \mathrm{m}$ filter and kept in a freezer for $48 \mathrm{~h}$ before being analyzed by ion chromatography to

(13) Hayes, J. E.; Simpson, R. J.; Richardson, A. E. Plant Soil 2000, 220, 165. (14) Shang, C. Caldwell, D. E. Stewart, J. W. B.; Tiessen, H.; Huang, P. M. Microb. Ecol. 1996, 31, 29.

(15) Fransson, A. M.; Jones, D. L. Soil Biol. Biochem. 2007, 39, 1213.

(16) Baldwin, D. S.; Beattie, J. K.; Coleman, L. M.; Jones, D. R. Environ. Sci Technol. 1995, 29, 1706.

(17) Baldwin, D. S.; Beattie, A. K.; Coleman, L. M. Environ. Sci. Technol. 2001, 35,713 .

(18) Guan, X. H.; Shang, C.; Zhu, J.; Chen, G. H. J. Colloid Interface Sci. 2006, 293, 296.

(19) Ognalaga, M.; Frossard, E.; Thomas, F. Soil Sci. Soc. Am. J. 1994, 58, 332

(20) Anderson, G.; Williams, E. G.; Moir, J. O. J. Soil Sci. 1974, 25, 51

(21) Loring, J. S.; Sandstrom, M. H.; Noren, K.; Persson, P. Chem-Eur. J. 2009, 15,5063 . determine the glucose concentration. Glucose recovery was $102 \%$ (pH 3.1), 102\% (pH 5.6), and 104\% (pH 9.6), with standard deviations of $3.1 \%, 4.9 \%$, and $0.6 \%$ respectively, based on two experimental series.

The synthesis and characterization of goethite $(\alpha-\mathrm{FeOOH})$ have been described previously. ${ }^{22}$ Briefly, goethite was prepared in polyethylene bottles by adding $2.5 \mathrm{M} \mathrm{KOH}$ (EKA, p.a.) to $10 \mathrm{~L}$ of $0.15 \mathrm{M} \mathrm{Fe}\left(\mathrm{NO}_{3}\right)_{3}$ (Merck, p.a.) at a rate of $10 \mathrm{~mL} / \mathrm{min}$. The precipitates were aged for $96 \mathrm{~h}$ at $60{ }^{\circ} \mathrm{C}$ and dialyzed for 2 weeks. The resulting particles were identified to be goethite by X-ray powder diffraction, and the specific surface area was determined to $86.9 \mathrm{~m}^{2} / \mathrm{g}$ using $\mathrm{N}_{2}$ Brunauer-Emmett-Teller (BET) analysis. The suspension was diluted and $\mathrm{NaCl}$ was added to give a $\mathrm{Na}(\mathrm{Cl})$ concentration of $50 \mathrm{mM}$.

2.2. Adsorption Experiments. The adsorption experiments were carried out in batch mode at two different total concentrations of G1P, in the $\mathrm{pH}$ range $3-10$ and at a background electrolyte concentration of $50 \mathrm{mM} \mathrm{Na}(\mathrm{Cl})$. The stock suspension of goethite was acidified to $\mathrm{pH} \sim 5$ and purged overnight with $\mathrm{N}_{2}(\mathrm{~g})$ to remove $\mathrm{CO}_{2}$. Each batch sample was prepared by transferring an aliquot of the stock goethite suspension to a $15 \mathrm{~mL}$ polypropylene centrifuge tube, adjusting the $\mathrm{pH}$ to a target value between 3 and 10 using acid or base and adding stock G1P solution. The final goethite concentration was $10 \mathrm{~g} / \mathrm{L}$. The total concentrations of G1P were 0.6 and $1.2 \mathrm{mM}$, corresponding to 0.69 and $1.38 \mu \mathrm{mol} / \mathrm{m}^{2}$ of goethite; with these concentrations, surface saturation was avoided, and sufficiently strong IR signals were obtained. During batch sample preparation, the centrifuge tubes were continuously purged with $\mathrm{N}_{2}(\mathrm{~g})$ to minimize carbonate contamination. To avoid photolysis of G1P, the centrifuge tubes were wrapped in aluminum foil. After equilibrating at $25^{\circ} \mathrm{C}$ on an end-over-end rotator for $1,6,24$, and $48 \mathrm{~h}$, the $\mathrm{pH}$ of each batch sample was measured with a combination electrode from Mettler Toledo (InLab 422) calibrated with commercial buffers (Baker) at $\mathrm{pH}=3,7$, and 9. Prior to quantitative measurements, the samples were centrifuged at $4000 \mathrm{rpm}$ for $15 \mathrm{~min}$ and the supernatant was filtered through a $0.2 \mu \mathrm{m}$ filter. The supernatant was immediately analyzed by ion chromatography for G1P, glucose, and phosphate. The amount of G1P adsorbed at the water-goethite interface was determined by measuring the concentration of the ligand remaining in the supernatant and subtracting this value from the total ligand concentration. A separate batch was made for the infrared measurements at a total G1P concentration of $1.38 \mu \mathrm{mol} / \mathrm{m}^{2}$. These samples were treated as described above. Infrared spectra were obtained of the supernatant and the wet mineral paste.

A control experiment in order to determine the extent of hydrolysis of G1P in the absence of goethite was performed. In this, batch samples with a G1P concentration of $1.35 \mathrm{mM}$ were prepared in the $\mathrm{pH}$ range $3-10$. The $\mathrm{pH}$ was adjusted with $\mathrm{HCl}$ and $\mathrm{NaOH}$, and $\mathrm{NaCl}$ was added to give a background electrolyte concentration of $50 \mathrm{mM} \mathrm{Na}(\mathrm{Cl})$. The degree of hydrolysis was determined by monitoring the phosphate level after $1,6,24,48$, and $96 \mathrm{~h}$.

2.3. Ion Chromatography. The concentrations of G1P, glucose, and phosphate in solution were determined by ion chromatography (IC). Data show that the extent of hydrolysis of G1P during the chromatographic analysis is negligible. G1P and phosphate were analyzed using a modular system from Metrohm equipped with a guard column (Metrosep RP), and followed by an anion-exchange column (Metrosep A SUPP 5-150) and a suppressor. The analytes were eluted isocratically with a mixture of $3.2 \mathrm{mM} \mathrm{Na} \mathrm{CO}_{3} / 1.0 \mathrm{mM} \mathrm{NaHCO}$ at a flow rate of $0.50 \mathrm{~mL} / \mathrm{min}$ and deionized water at a flow rate of $0.20 \mathrm{~mL} /$ min. Glucose was determined on a Dionex system (ICS-3000) with a CarboPac PA 20 guard column followed by a CarboPac PA 20 column, and a $20 \mathrm{mM} \mathrm{NaOH}$ eluent.

22) Boily, J. F.; Lutzenkirchen, J.; Balmes, O.; Beattie, J.; Sjoberg, S. Colloids Surf., A 2001, 179, 11 
2.4. Infrared Spectroscopy. The infrared spectra were recorded using attenuated total reflectance Fourier transform infrared (ATR FTIR) spectroscopy. Spectra were collected with a Bruker IFS66 v/s instrument and a 9 internal reflections horizontal ATR accessory with an internal reflection element consisting of diamond/KRS5 (SensIR Technologies). The angle of incidence for this ATR cell is $\sim 45^{\circ}$. For each batch sample, a background spectrum of the empty ATR cell was collected, and subsequently spectra were measured of both the filtered supernatant solution and the wet mineral paste. Spectra were an average of 512 scans that were collected at a resolution of $4 \mathrm{~cm}^{-1}$. The absorbance spectrum of a wet mineral paste of a batch sample includes contributions from adsorbed ligand, ligand in solution, and bulk water (ionic medium). To isolate the spectrum of the adsorbed ligand, the absorbance spectrum of the batch sample's supernatant was subtracted from the corresponding wet mineral paste spectrum in order to remove the contributions from bulk water.

Desorption data were collected using an experimental setup for simultaneous infrared and potentiometric titration (SIPT), which has been described by Loring et al. ${ }^{21}$ A goethite suspension was pumped peristaltically in a closed loop through fluoroelastomer (Chemsure Gore Industries) and PTFE tubing from a thermostatted $\left(25 \pm 0.05^{\circ} \mathrm{C}\right)$ titration vessel to a flow-through ATR cell. The flow-through attachment was custom built of inert materials (e.g., Pyrex glass, PEEK, PTFE) and mounted on a single-reflection $\mathrm{ZnSe} 45^{\circ}$ ATR accessory (FastIR, Harrick Scientific). A goethite overlayer was deposited onto the $\mathrm{ZnSe}$ crystal by evaporating $0.7 \mathrm{~mL}$ of a mineral suspension (ca. $2.5 \mathrm{~g} / \mathrm{L}$ ) onto the crystal at $75^{\circ} \mathrm{C}$ for $2.5 \mathrm{~h}$ under a $\mathrm{N}_{2}$-atmosphere. The ATR cell was placed inside an evacuated ( $5 \mathrm{mbar}$ ) infrared spectrometer (Bruker IFS66 $\mathrm{v} / \mathrm{s}$ in a thermostatted room $25 \pm 0.15{ }^{\circ} \mathrm{C}$ ) equipped with a deuterated triglycine sulfate (DTGS) detector and a water-cooled Globar source.

A volume of $50 \mathrm{~mL}$ of a $12.9 \mathrm{~g} / \mathrm{L}$ goethite suspension was pipetted into the titration vessel and pumped over the overlayer. The $\mathrm{pH}$ was adjusted to 9.3 and was kept constant with an automated and computer controlled buret system. A background spectrum of 4096 scans was collected of the overlayer and the goethite suspension. A volume of G1P solution was added to reach a total concentration of 1.36 or $0.69 \mu \mathrm{mol} / \mathrm{m}^{2}$, and the $\mathrm{pH}$ was adjusted to 5.0 or 8.5. Sample absorbance spectra (512 scans) were collected as a function of time to follow the adsorption of G1P, and the adsorption reaction was assumed to be equilibrated after approximately $2.5 \mathrm{~h}$. The change in peak intensities in consecutive spectra, collected 8 min apart, was then $1 \%$ or less of the total peak intensities.

After the adsorption reaction had equilibrated, an aliquot of the suspension was collected to measure the adsorbed ligand concentration. The ligand-containing suspension was then pumped into a waste container, and the peristaltic pump was shut down. The only ligand-containing suspension that remained was approximately $2 \mathrm{~mL}$ in the flow-through ATR cell; adsorbed ligands also covered the goethite overlayer on the ATR crystal. Next, $60 \mathrm{~mL}$ of a ligand-free goethite suspension was pipetted into the clean titration vessel, this was titrated to $\mathrm{pH} 5.0$ or 8.5 , and the peristaltic pump was restarted. The first $10 \mathrm{~mL}$ of ligand-free suspension pumped into the flow-through cell was used only to flush the ligand-containing suspension out of the cell, and this was collected in a waste container. The goethite overlayer remains during this flushing process. The remaining $50 \mathrm{~mL}$ of ligand-free suspension was then pumped in a closed loop. Infrared spectra were collected as a function of time to follow the desorption of G1P from the goethite in the overlayer, starting when ligand-free suspension was first pumped into the flow-through cell.

The infrared radiation in the form of an exponentially decreasing evanescent wave is most intense at the interface between the $\mathrm{ZnSe}$ crystal and the goethite overlayer. This means that practically the entire signal in the infrared spectra is from the ligand adsorbed on the goethite in the overlayer, and the signal from the ligand adsorbed on the goethite in the suspension is negligible.
Thus, the observed decrease in the absorbance as a function of time is a result of G1P desorbing from the goethite in the overlayer and subsequently adsorbing onto the goethite in the suspension. The described experimental procedure is similar to that used in a recent study on desorption kinetics. ${ }^{23}$ One main difference however is that these authors studied desorption from the overlayer to an aqueous solution, while herein we analyzed desorption to an initially ligand-free goethite suspension.

At first, 16-scan spectra were collected to capture the rapid initial desorption. As the reaction slowed down, a larger number of scans were collected for each spectrum. Data collection was continued for various lengths of time depending on the rate of desorption in the particular experiment. The desorption results were initially evaluated by integrating the peak area between 1000 and $1200 \mathrm{~cm}^{-1}$, and by normalizing to the area at $t=0$, that is, to the spectrum collected immediately before the desorption reaction. The spectral data sets from desorption experiments were further analyzed using a singular value decomposition (SVD) formalism as implemented in Olis GlobalWorks (Olis, Inc.). The number of spectra included in the SVD analysis varied depending on the total concentration of G1P and $\mathrm{pH}$, but encompassed a minimum of 250 spectra. The number of species to fit were decided based on two criteria: (1) visual inspection of the kinetic eigenvectors where a random and flat appearance indicated insignificant contribution; (2) log plot of weight percentage of the kinetic eigenvectors versus eigenvector number where deviations from a linear function indicate the number of significant species. Based upon the number of species, various kinetic models were attempted to fit the kinetic spectral data sets. These models were evaluated from the residual plot (i.e., the difference between the experimental total absorbance decay and the calculated values) as well as the calculated spectra which should show positive peaks only.

2.5. Two-Dimensional (2D) Infrared Correlation Spectroscopy. The infrared spectra were analyzed by means of the general 2D correlation spectroscopy formalism as implemented in the code 2D Shige. ${ }^{24}$ The spectra were truncated at 1250 and $930 \mathrm{~cm}^{-1}$, and baseline corrected by fitting a straight line through two points at 1250 and $1200 \mathrm{~cm}^{-1}$ where the samples did not display any peaks. This procedure adjusted the spectra to the same $y$-axis zero level. The obtained spectral data set displays variation as a function of $\mathrm{pH}$, which is caused by changes in the total amount of ligand adsorbed and in the relative distribution of different surface species. The objective of the 2D correlation analysis was primarily to study the latter effect; hence, the variation in total surface concentration was significantly reduced by normalizing the main peak in the interval $1160-1120 \mathrm{~cm}^{-1}$ to the same height in all spectra. Subsequently, the truncated, baseline-corrected, and normalized spectral data set was used to calculate synchronous and asynchronous 2D correlation plots. The synchronous plot was analyzed by identifying the diagonal auto peaks and the off-diagonal cross peaks. The former provide information on peaks responsible for the major spectral variation as a function of $\mathrm{pH}$, while the latter are a measure of the correlated response to the $\mathrm{pH}$ perturbation at two different wavenumbers. ${ }^{25}$ The asynchronous plot does not contain auto peaks, but the off-diagonal cross peaks in this plot show the uncorrelated peak responses, which are partly or completely out-of-phase, as a function of the pH perturbation. ${ }^{25}$ The collective information provided by the $2 \mathrm{D}$ correlation spectroscopy analysis indicates which peaks belong to the same surface species and also the number of dominating species. $^{26-28}$

(23) Young, A. G.; McQuillan, A. J. Langmuir 2009, 25, 3538

(24) Morita, S. Software 2Dshige; Kwansei-Gakuin University: 2004-2005.

(25) Noda, I.; Ozaki, Y. Two-dimensional correlation spectroscopy: Applications in vibrational and optical spectroscopy: John Wiley \& Sons: Chichester, West Sussex, England, 2004

(26) Norén, K.; Persson, P. Geochim. Cosmochim. Acta 2007, 71, 5717.

(27) Norén, K.; Loring, J. S.; Bargar, J. R.; Persson, P. J. Phys. Chem. C 2009. 113,7762

(28) Lindegren, M.; Loring, J. S.; Persson, P. Langmuir 2009, 25, 10639. 
2.6. Molecular Orbital Calculations. Gaussian $03^{29}$ was used to perform a geometry optimization and calculate the infrared spectrum of deprotonated G1P $\left(\mathrm{L}^{2-}\right)$ in aqueous solution. The solution environment was simulated by 10 explicit water molecules. The ONIOM option of Gaussian was used, and the calculation of G1P was based on the B3LYP/6-311++G(d,p) model chemistry, while the water molecules were treated at the semiempirical AM1 level. Only positive frequencies were observed, indicating that the optimized structure represents a minimum in the potential energy surface. Visualization of the atomic displacements corresponding to each calculated frequency was performed with Gauss View. ${ }^{29}$

\section{Results and Discussion}

The collective spectroscopic results presented herein show that G1P forms $\mathrm{pH}$-dependent surface complexes on goethite. We propose that there are three dominant classes of monodentate complexes that differ with respect to hydrogen bonding interactions with the surface and desorption kinetics. We also show that adsorbed G1P is relatively stable and that surface promoted hydrolysis is of minor importance under the experimental conditions studied herein. In the following text, these findings are detailed.

3.1. Adsorption of G1P on Goethite as a Function of $\mathrm{pH}$ and Time. The acid-base property of G1P is characterized by two $\mathrm{p} K_{\mathrm{a}}$ values at 1.2 and 6.1 ; thus, within the studied $\mathrm{pH}$ range (3-10), G1P exists in solution either as a mono- or divalent anion ( $\mathrm{HL}^{-}$and $\mathrm{L}^{2-}$, respectively). In accordance with this anionic property, the results from the batch experiments show that adsorption of G1P on goethite is typical of an anion; that is, adsorption increases as $\mathrm{pH}$ decreases (Figure 1). ${ }^{30}$ In the acidic $\mathrm{pH}$ range, adsorption is almost constant and practically all G1P ions are absorbed at both total concentrations studied. The fact that G1P adsorption occurs over a wide $\mathrm{pH}$ interval and at $\mathrm{pH}$ values above the isoelectric point of goethite $\left(\right.$ IEP $\left._{\text {goethite }}=9.4\right)$ indicates a comparatively strong interaction with the particle surfaces. In the neutral to acidic region, the adsorption curves resemble those of inorganic oxoanions such as phosphate (Figure 1) and arsenate, ${ }^{21}$ tentatively suggesting similar surface coordination modes. One difference, however, is that adsorption of phosphate and arsenate extends at even higher $\mathrm{pH}$ values, suggesting an even stronger association with goethite.

The adsorption curves collected as a function of time are practically identical (Figure 1), which shows that adsorption of G1P onto goethite is a comparatively rapid process; the equilibrium in the total amount of adsorbed G1P seems to be reached within $1 \mathrm{~h}$ of reaction time. As surface transformation and surface precipitation reactions typically are slower this result indicates that G1P forms surface complexes on goethite. ${ }^{31}$ At $\mathrm{pH} 9$ and 10,

(29) Frisch, M. J.; Trucks, G. W.; Schlegel, H. B.; Scuseria, G. E.; Robb, M. A.; Cheeseman, J. R.; Montgomery, J. A., Jr.; Vreven, T.; Kudin, K. N.; Burant, J. C.; Millam, J. M.; Iyengar, S. S.; Tomasi, J.; Barone, V.; Mennucci, B.; Cossi, M.; Scalmani, G.; Rega, N.; Petersson, G. A.; Nakatsuji, H.; Hada, M.; Ehara, M.; Toyota, K.; Fukuda, R.; Hasegawa, J.; Ishida, M.; Nakajima, T.; Honda, Y.; Kitao, O.; Nakai, H.; Klene, M.; Li, X.; Knox, J. E.; Hratchian, H. P.; Cross, J. B.; Bakken, V.; Adamo, C.; Jaramillo, J.; Gomperts, R.; Stratmann, R. E.; Yazyev, O.; Austin, A. J.; Cammi, R.; Pomelli, C.; Ochterski, W. J.; Ayala, P. Y.; Morokuma, K.; Voth, G. A.; Salvador, P.; Dannenberg, J. J.; Zakrzewski, V. G.; Dapprich, S.; Daniels, A. D.; Strain, M. C.; Farkas, O.; Malick, D. K.; Rabuck, A. D.; Raghavachari, K.; Foresman, J. B.; Ortiz, J. V.; Cui, Q.; Baboul, A. G.; Clifford, S.; Cioslowski, J.; Stefanov, B. B.; Liu, G.; Liashenko, A.; Piskorz, P.; Komaromi, I.; Martin, R. L.; Fox, D. J.; Keith, T.; Al-Laham, M. A.; Peng, C. Y.; Nanayakkara, A.; Challacombe, M.; Gill, W. P. M.; Johnson, B.; Chen, W.; Wong, M. W.; Gonzalez, C.; Pople, J. A. Gaussian 03, revision; Gaussian Inc.: Wallingford, CT, 2004.

(30) Stumm, W. Chemistry of the solid-water interface: Processes at the mineralwater and particle-water interface in natural systems; Wiley: New York, 1992.

(31) Sposito, G. The surface chemistry of natural particles; Oxford University Press: New York, 2004.

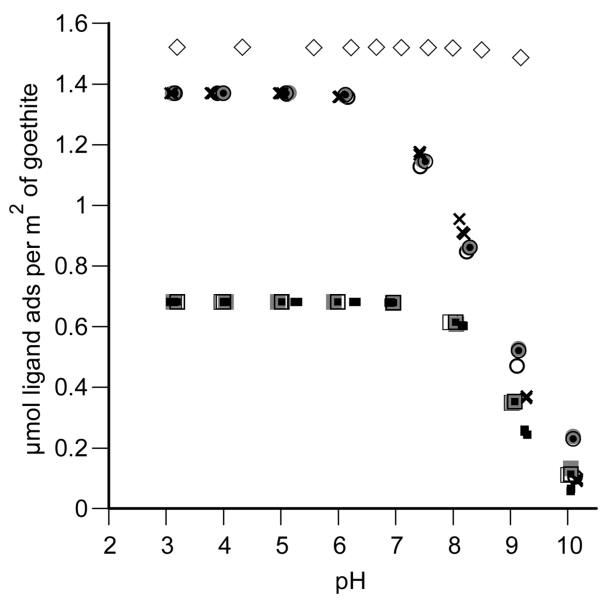

Figure 1. Adsorption of G1P on goethite as a function of $\mathrm{pH}$ and time. Samples with a total concentration of $1.38 \mu \mathrm{mol} / \mathrm{m}^{2}$ of goethite are denoted: $(O) 1 \mathrm{~h}$, (solid gray circle) $6 \mathrm{~h}$, (circle with inset solid circle) $24 \mathrm{~h}$, and $(\times) 48 \mathrm{~h}$. Samples with a total concentration of $0.69 \mu \mathrm{mol} / \mathrm{m}^{2}$ of goethite are denoted: $(\square) 1 \mathrm{~h}$, (gray solid square) $6 \mathrm{~h}$, (square with inset solid square) $24 \mathrm{~h}$, and (ם) 48 h. $(\diamond)$ Adsorbed orthophosphate at a total concentration of 1.53 $\mu \mathrm{mol} / \mathrm{m}^{2}$ of goethite, after an equilibration time of $24 \mathrm{~h}$.

slightly less G1P seems to be adsorbed in the $48 \mathrm{~h}$ samples compared to the samples with shorter reaction times. This may be due to contamination by atmospheric $\mathrm{CO}_{2}$, causing competition between carbonate and G1P for adsorption sites, but we were unable to detect carbonate surface species by means of IR spectroscopy. Thus, it may simply be an effect of the experimental errors in the G1P analysis due to the fact the most G1P is remaining in solution above $\mathrm{pH} 9$.

3.2. Infrared Spectroscopic Characterization of G1P Surface Complexes. The infrared spectra of the G1P solution species $\left(\mathrm{HL}^{-}\right.$and $\left.\mathrm{L}^{2-}\right)$ are important for the interpretations of the IR spectral features of the surface complexes. Often the most diagnostic peaks of phosphates are the $\mathrm{P}-\mathrm{O}$ stretching modes that typically appear in the frequency region between 800 and $1300 \mathrm{~cm}^{-1}$. In the case of G1P, this region is complicated by the fact that the glucose moiety also absorbs infrared radiation in this region. The density functional theory (DFT) calculations indicate, however, that the coupling between the $\mathrm{P}-\mathrm{O}$ vibrations and the vibrations of the glucose group is not very substantial, and it seems that the phosphorus atom acts as a partial coupling barrier due to its larger mass. Accordingly, IR peaks of G1P in the region $800-1300 \mathrm{~cm}^{-1}$ may be assigned either as predominately phosphate or glucose vibrations (Figure 2 and Table 1). It also follows that peak assignments of $\mathrm{L}^{2-}$ and $\mathrm{HL}^{-}$may be facilitated by comparison with spectra of $\mathrm{O}_{3} \mathrm{POX}$ and $\mathrm{O}_{2} \mathrm{PO}_{2} \mathrm{X}_{2}$ molecules, respectively. Of particular interest is comparison with $\mathrm{HPO}_{4}{ }^{2-}$ and $\mathrm{H}_{2} \mathrm{PO}_{4}{ }^{-}$, as these only show $\mathrm{P}-\mathrm{O}$ stretching vibrations in the region between 800 and $1300 \mathrm{~cm}^{-1}$, except for a weak and broad $\mathrm{P}-\mathrm{O}-\mathrm{H}$ bending mode, and therefore help separate the $\mathrm{P}-\mathrm{O}$ peaks from those originating from glucose. As shown in Figure 2, except for peak shifts, the $\mathrm{P}-\mathrm{O}$ stretching modes of the non- and monoprotonated forms of G1P are similar to those of $\mathrm{HPO}_{4}{ }^{2-}$ and $\mathrm{H}_{2} \mathrm{PO}_{4}{ }^{-}$, respectively. Hence, G1P seems to respond to coordination changes in the same fashion as orthophosphate and the related oxoanion arsenate, ${ }^{21}$ and in accordance with these oxoanions the protonation effects of G1P show that the highest frequency $\mathrm{P}-\mathrm{O}$ stretch shifts to higher frequency at each protonation step (Figure 2). A summary of the G1P peak assignments is provided in Table 1. 


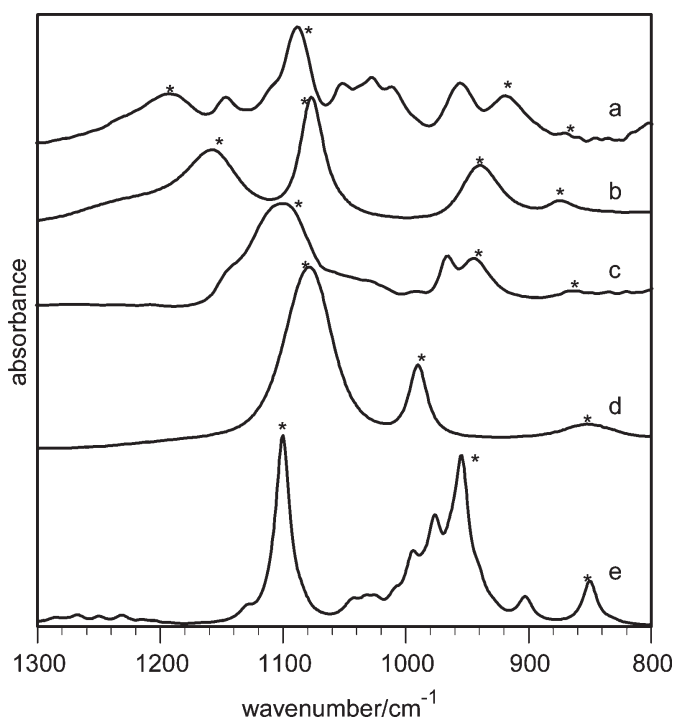

Figure 2. Infrared spectra of (a) monoprotonated $\mathrm{G} 1 \mathrm{P}\left(\mathrm{HL}^{-}\right)$in aqueous solution, (b) dihydrogen phosphate $\left(\mathrm{H}_{2} \mathrm{PO}_{4}{ }^{-}\right)$in aqueous solution, (c) deprotonated G1P ( $\mathrm{L}^{2-}$ ) in aqueous solution, (d) monohydrogen phosphate $\left(\mathrm{HPO}_{4}{ }^{2-}\right)$ in aqueous solution, and (e) the DFT-calculated spectrum of deprotonated G1P $\left(\mathrm{L}^{2-}\right)$ explicitly solvated by 10 water molecules. The theoretical spectrum was simulated assuming a Lorentzian line shape and full width at half-maximum of $15 \mathrm{~cm}^{-1}$. The peaks assigned to $\mathrm{P}-\mathrm{O}$ stretching modes are labeled with an asterisk $(*)$.

Table 1. Experimental Infrared Frequencies $\left(\right.$ in $\left.\mathrm{cm}^{-1}\right)$ of the Non- and Monoprotonated Forms of Glucose-1-phosphate in Aqueous Solution Together with Tentative Group Assignments ${ }^{a}$

\begin{tabular}{rrl}
\hline $\mathrm{L}^{2-}$ & $\mathrm{HL}^{-}$ & group assignment \\
\hline & 1190 & phosphate mode \\
1145 & 1147 & glucose mode \\
1112 & 1114 & glucose mode \\
1094 & 1088 & phosphate mode \\
1055 & 1053 & glucose mode \\
1026 & 1030 & glucose mode \\
993 & 1009 & glucose mode \\
967 & 957 & glucose mode \\
945 & 919 & phosphate mode \\
864 & 871 & phosphate mode
\end{tabular}

${ }^{a}$ The group assignments are based on comparison with the infrared spectra of $\mathrm{HPO}_{4}{ }^{2-}(\mathrm{aq}), \mathrm{H}_{2} \mathrm{PO}_{4}{ }^{-}(\mathrm{aq})$, and glucose (aq) as well as with the results from the molecular orbital calculations of G1P $10 \mathrm{H}_{2} \mathrm{O}$. Some of the listed peaks are only detected as shoulders in the original spectra (Figure 2), and these were further resolved in the second derivatives (not shown).

The infrared spectra of G1P adsorbed onto goethite display some marked differences in comparison with the solution spectra (Figures 2 and 3). At the same time, we detect peaks in the regular IR spectra (Figure 3) and the corresponding second derivates (not shown) at 972, 995, 1085, and $1107 \mathrm{~cm}^{-1}$, in close agreement with peaks originating from the glucose moiety of the solution species (Table 1). Accordingly, we ascribe the major changes in the surface spectra, manifested as new strong peaks around 1030 and $1150 \mathrm{~cm}^{-1}$, to $\mathrm{P}-\mathrm{O}$ vibrations. This indicates significant distortions of the $\mathrm{P}-\mathrm{O}$ bonds as G1P coordinates to goethite, which is consistent with the formation of inner sphere surface complexes and in agreement with adsorption of other phosphates,

(32) Tejedortejedor, M. I.; Anderson, M. A. Langmuir 1990, 6, 602.

(33) Persson, P.; Nilsson, N.; Sjoberg, S. J. Colloid Interface Sci. 1996, 177, 263.

(34) Sheals, J.; Sjoberg, S.; Persson, P. Environ. Sci. Technol. 2002, 36, 3090.

(35) Manceau, A. Geochim. Cosmochim. Acta 1995, 59, 3647.

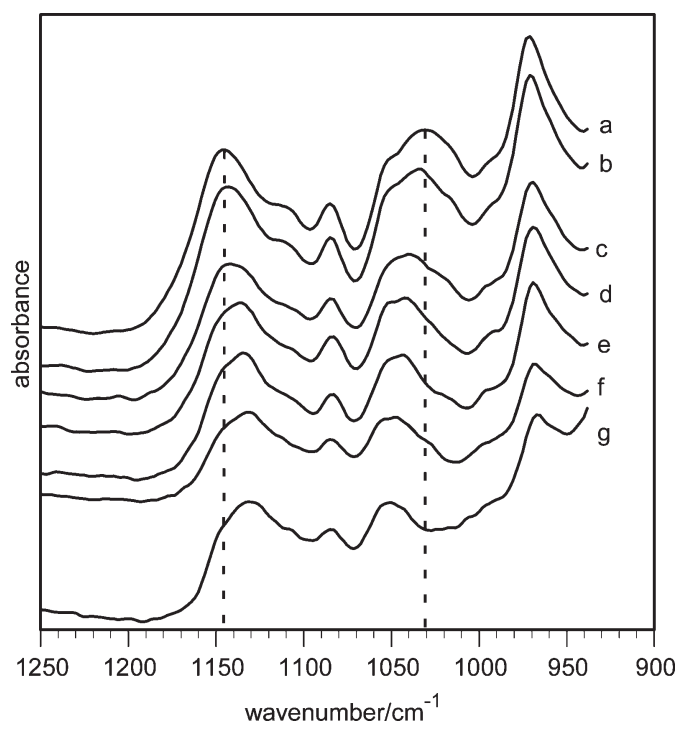

Figure 3. Infrared spectra of G1P adsorbed on goethite at $\mathrm{pH}$ (a) 2.99 , (b) 4.04 , (c) 4.95, (d) 6.16, (e) 7.16, (f) 8.11, and (g) 9.04. The reaction time was $48 \mathrm{~h}$, and the total concentration of G1P was $1.38 \mu \mathrm{mol} / \mathrm{m}^{2}$ goethite. The ordinate scale is arbitrary and has been adjusted for each spectrum to facilitate qualitative comparisons.

phosphonates, and the analogous arsenates onto iron oxides. ${ }^{21,32-38}$ The infrared spectra also reveal $\mathrm{pH}$-dependent features of the $\mathrm{P}-\mathrm{O}$ modes; at low $\mathrm{pH}$, the spectra are characterized by peaks at ca. 1030 and $1150 \mathrm{~cm}^{-1}$, while the high-pH spectra display corresponding peaks at ca. 1050 and $1130 \mathrm{~cm}^{-1}$, respectively. In order to explain these spectral changes, we need to invoke the existence of at least two different G1P surface complexes.

3.3. 2D Correlation Analysis of Infrared Spectra of G1P Surface Complexes. The synchronous 2D correlation analysis of the G1P-goethite spectra indicates a minimum of two predominating surface complexes and thus corroborates the observations made from the regular IR spectra (Figure 3). Nine auto peaks are detected in the synchronous 2D contour map and the diagonal slice spectrum (not shown) at 965, 986, 1015, 1046, 1058, $1078,1098,1129$, and $1160 \mathrm{~cm}^{-1}$ (Figure 4), and according to the cross peaks these peaks form two distinctive groups. The peaks at $965,1046,1058,1078,1098$, and $1129 \mathrm{~cm}^{-1}$ all show mutual positive cross peaks while they are negatively correlated to the 986 , 1015 , and $1160 \mathrm{~cm}^{-1}$ peaks; the latter group also displays common positive cross peaks (Table 2). Accordingly, these groups of peaks originate from two different G1P surface complexes. Five of the auto peaks appear in the regions of major $\mathrm{pH}$ dependent spectral change around 1050 and $1130 \mathrm{~cm}^{-1}$; thus, it is likely that the correlated peaks at $(1015,1160)$ and $(1046,1058$, 1129 ) originate predominately from $\mathrm{P}-\mathrm{O}$ modes. However, based on the unshifted character of the glucose groups, frequencies possibly either the 1046 or 1058 peak in the latter group originate from the glucose moiety. Note that the exact wavenumbers of the peaks detected in the regular spectra and those detected in the 2D analysis may differ slightly, which means that the wavenumber where maximum change occurs according to the $2 \mathrm{D}$ analysis does not exactly correspond to the apparent peak maxima detected in the regular spectra. This may be caused by the complex spectral

(36) Waychunas, G.; Trainor, T.; Eng, P.; Catalano, J.; Brown, G.; Davis, J.; Rogers, J.; Bargar, J. Anal. Bioanal. Chem. 2005, 383, 12.

(37) Waychunas, G. A.; Rea, B. A.; Fuller, C. C.; Davis, J. A. Geochim. Cosmochim. Acta 1993, 57, 2251.

(38) Sherman, D. M.; Randall, S. R. Geochim. Cosmochim. Acta 2003, 67, 4223. 

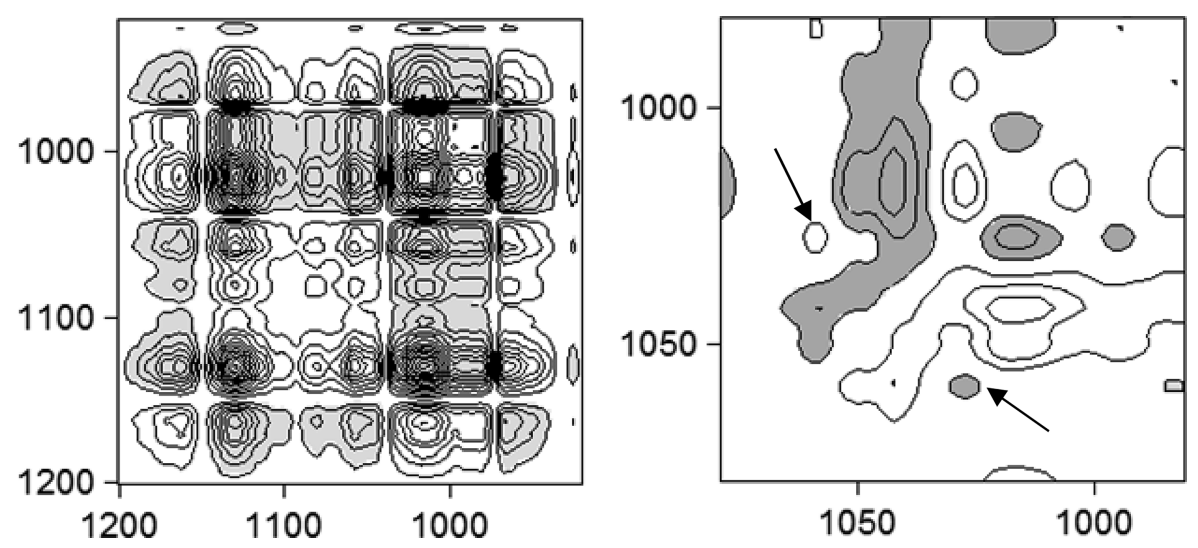

Figure 4. Synchronous (left) and asynchronous (right) contour maps obtained from a 2D correlation analysis of the infrared spectra presented in Figure $3 \mathrm{a}-\mathrm{f}$. The abscissa and ordinate scales are given in $\mathrm{cm}^{-1}$, and the white and gray areas denote positive and negative responses, respectively. The arrows highlight the weak cross peaks associated with the characteristic distorted butterfly pattern.

Table 2. Summary of the Synchronous 2D Correlation Spectroscopy Results of G1P Adsorbed onto Goethite ${ }^{a}$

\begin{tabular}{lllllllllll}
\hline & 965 & 986 & 1015 & 1046 & 1058 & 1078 & 1098 & 1129 & 1160 \\
\hline 965 & + & - & - & + & + & + & + & + & - \\
986 & - & + & + & - & - & - & - & - & + \\
1015 & - & + & + & - & - & - & - & - & + \\
1046 & + & - & - & + & + & + & + & + & - \\
1058 & + & - & - & + & + & + & + & + & - \\
1078 & + & - & - & + & + & + & + & + & - \\
1098 & + & - & - & + & + & + & + & + & - \\
1129 & + & - & - & + & + & + & + & + & - \\
1160 & - & + & + & - & - & - & - & - & +
\end{tabular}

${ }^{a}$ The auto peaks along the diagonal (from upper right to lower left) and the off-diagonal cross peaks are given in $\mathrm{cm}^{-1}$.

shapes consisting of several overlapping and rather broad peaks, particularly apparent around $1030 \mathrm{~cm}^{-1}$. While the $(1015,1160)$ and $(1046,1058,1129)$ groups primarily originating from $\mathrm{P}-\mathrm{O}$ modes are consistent with the major $\mathrm{pH}$-dependent changes observed in the regular spectra, the changes of the remaining synchronous 2 D peaks at $965,986,1078$, and $1098 \mathrm{~cm}^{-1}$ are not as obvious in these spectra (Figure 3). These peaks are detected in all regular spectra, and no appreciable shifts are observed; thus, the 2D effects must originate from intensity variations relative to the other peaks of each surface complex. This may be caused by the normalization procedure or by real changes of the absorption coefficients, or both. In any case, by comparison with the spectra of the solution species (Table 1), it is likely that the peaks at 965 , 986,1078 , and $1098 \mathrm{~cm}^{-1}$ originate predominately from vibrations of the glucose moiety.

The asynchronous contour plot displays rather weak features. However, one discernible feature is a so-called distorted butterfly pattern in the region between 1010 and $1060 \mathrm{~cm}^{-1}$ with asymmetrically elongated cross peaks near the diagonal distributed closer to the stronger synchronous auto peak, that is, the $1015 \mathrm{~cm}^{-1}$ peak (Figure 4). This feature together with a secondary pair of weak cross peaks (marked with arrows in Figure 4) indicates that the asynchronous feature is generated from complex peak changes and not simply intensity changes of two overlapping peaks. ${ }^{25}$ Instead, these features suggest peak shifts coupled to variations in peak widths. Hence, the surface speciation is probably more complex than just two interchanging species and includes one or several intermediate complexes in addition to the two that were detected in the synchronous analysis. The existence of more than two types of surface complexes is in agreement with results from the desorption experiments as will be discussed below.

3.4. Structural Assignment of G1P Surface Complexes. As discussed, the perturbations of the $\mathrm{P}-\mathrm{O}$ stretching modes in comparison with the solution species indicate inner sphere coordination between the phosphate group of G1P and Fe(III) at the surface of goethite. The spectral features of the surface complexes with two predominating $\mathrm{P}-\mathrm{O}$ peaks in the region between 1000 and $1200 \mathrm{~cm}^{-1}$ is similar to the spectrum of $\mathrm{HL}^{-}$in solution (Figure 2); however, in the former case, the peaks are redshifted by approximately $50 \mathrm{~cm}^{-1}$. The similarity with the $\mathrm{HL}^{-}$ species tentatively suggests monodentate coordination between G1P and iron; that is, the proton of $\mathrm{HL}^{-}$is replaced by a surface $\mathrm{Fe}(\mathrm{III})$. The surface coordination modes of phosphates/phosphonates and the analogous arsenate have been intensely discussed in the literature, and both bridging bidentate and monodentate interpretations have been favored. ${ }^{21,32-38}$ In a recent study, it was shown by combining a range of spectroscopic and diffraction methods that arsenate coordinates to goethite as predominately monodentate complexes and that these surface complexes are stabilized by additional hydrogen bonding. ${ }^{21}$ New studies on competitive adsorption have also indicated the importance of monodentately and hydrogen bonded surface complexes of phosphate on goethite..$^{39,40}$ The spectroscopic results of G1P adsorbed onto goethite are in accordance with these recent findings. In particular the $\mathrm{pH}$-dependent spectral changes and the similarity with the $\mathrm{P}-\mathrm{O}$ peaks of $\mathrm{HL}^{-}$are explained by a structural model incorporating monodentate coordination to iron in combination with hydrogen bonding to neighboring surface sites.

The infrared spectra in Figure 3 show that the highestwavenumber $\mathrm{P}-\mathrm{O}$ stretching peak experiences a blue-shift from ca. 1130 to ca. $1150 \mathrm{~cm}^{-1}$ with decreasing $\mathrm{pH}$. Similar or larger blue-shifts are observed as phosphate or arsenate, or metal complexes of these ions, are gradually protonated. ${ }^{21,32}$ This is due to the fact that the highest frequency $\mathrm{P}(\mathrm{As})-\mathrm{O}$ peak originates from vibrational modes that involve the atoms in the strongest $\mathrm{P}(\mathrm{As})-\mathrm{O}$ bonds (i.e., the $\mathrm{P}(\mathrm{As})-\mathrm{O}$ groups that do not interact with protons or metal ions) and the bonds strengths of these are increased as the other oxygens are protonated. This relationship is valid as long as there at least is one "free" $\mathrm{P}(\mathrm{As})-\mathrm{O}$ group, but when all oxygens are bonded to either metal ions or protons, as for $\mathrm{H}_{4} \mathrm{PO}_{4}{ }^{+}$, the highest $\mathrm{P}-\mathrm{O}$ frequency experiences a

(39) Lindegren, M.; Persson, P. Eur. J. Soil Sci. 2009, 60, 982

(40) Lindegren, M.; Persson, P. J. Colloid Interface Sci. 2010, 343, 263. 

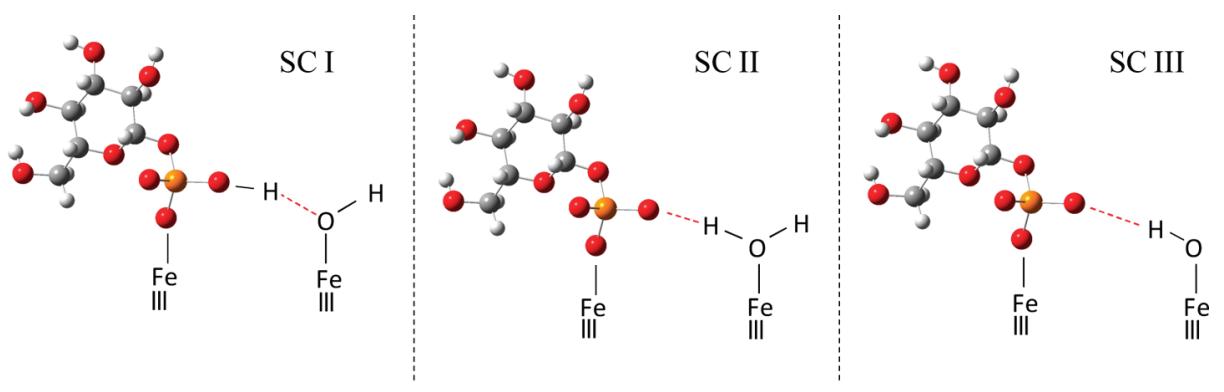

Increasing pH

Figure 5. Proposed structures of G1P surface complexes on goethite in agreement with the infrared spectroscopic data. The dotted red lines denote hydrogen bonding.

dramatic red-shift. ${ }^{41}$ In line with these empirical trends, the shift from 1130 to $1150 \mathrm{~cm}^{-1}$ of the highest frequency $\mathrm{P}-\mathrm{O}$ peak of adsorbed G1P as a function of decreasing $\mathrm{pH}$ implies that the bond strength of at least one of the "free" $\mathrm{P}-\mathrm{O}$ increases as a result of an interaction with the remaining G1P phosphate oxygens. However, a direct protonation of Fe(III)-coordinated G1P similar to protonation in solution is unlikely, as this should result in a high frequency $\mathrm{P}-\mathrm{O}$ mode that is expected to be slightly higher than that of $\mathrm{HL}^{-}$in solution at $1196 \mathrm{~cm}^{-1}$. Instead, we propose a structural model where a monodentately coordinated G1P interacts via hydrogen bonding to a neighboring site, and that this interaction becomes gradually stronger with decreasing $\mathrm{pH}$ and finally the proton may be located closer to G1P. Thus, G1P changes from a H-bonding acceptor to a donor. Schematic structures of possible coordination modes are depicted in Figure 5, where the difference in surface interaction is suggested to originate from the difference between a singly and a doubly protonated surface oxygen as H-bond donors or acceptors. This is a simplistic view, and of course differences in H-bonding may be due to other neighboring sites or combination of sites. Still the proposed structural model is fully consistent with the infrared spectroscopic results and most likely captures many important features of the structures of the surface complexes. For instance, the gradual proton shift from SC III via SC II to SC I (Figure 5) is in agreement with the seemingly shifting peaks indicated by the asynchronous $2 \mathrm{D}$ results. One may question whether a protonated G1P surface species is formed as the highest frequency $\mathrm{P}-\mathrm{O}$ mode of this species appears between 1150 and $1160 \mathrm{~cm}^{-1}$ whereas as the corresponding mode of the $\mathrm{HL}^{-}$in solution is detected at $1196 \mathrm{~cm}^{-1}$, which according to the discussion above indicates a greater bond strength of the free $\mathrm{P}-\mathrm{O}$ in the latter. Thus, if a protonated G1P surface species exists, it must interact substantially stronger with its neighboring environment via a $\mathrm{H}$-donor interaction in comparison with the solution species. Based on the present data, we cannot conclude whether a complete proton transfer occurs; however, still we favor the proposed structural model with the three species as it is also in agreement with the desorption results presented below.

It should be pointed out that the observed $\mathrm{pH}$-dependent shift of the $\mathrm{P}-\mathrm{O}$ modes contradicts a bridging bidentate model. This structure contains only one nonbonded $\mathrm{P}-\mathrm{O}$ group; thus, in order to produce the observed peak shift, H-bonding to this G1P oxygen should be stronger at high $\mathrm{pH}$, causing the detected red-shift. This is unlikely as the surface protonation increases with decreasing $\mathrm{pH}$ which should increase the density of acidic protons and thereby the density of strong $\mathrm{H}$ donors.

(41) Minkwitz, R.; Schneider, S. Angew. Chem., Int. Ed. 1999, 38, 210.

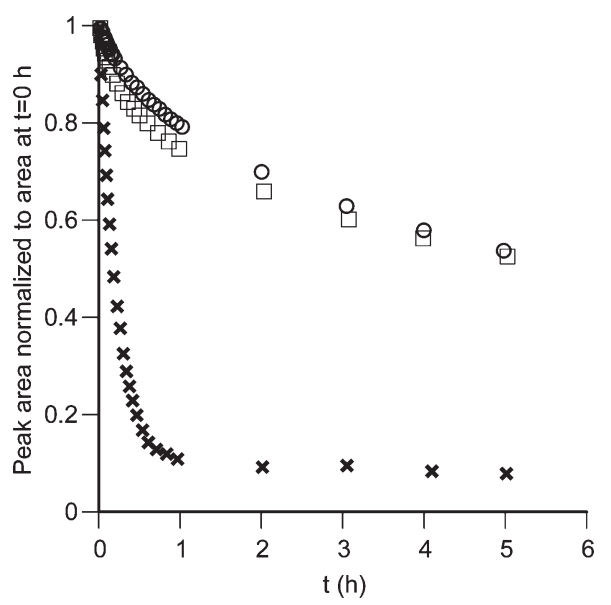

Figure 6. Normalized integrated peak areas of G1P adsorbed on goethite, as a function of time: $(O)$ total concentration of $0.69 \mu \mathrm{mol} / \mathrm{m}^{2}$ of goethite and $(\square)$ total concentration of $1.36 \mu \mathrm{mol} / \mathrm{m}^{2}$ of goethite, both at $\mathrm{pH}$ 5.0. $(\times)$ Total concentration of $1.36 \mu \mathrm{mol} / \mathrm{m}^{2}$ at $\mathrm{pH} 8.5$.

Furthermore, according to the adsorption curves (Figure 1), adsorption density decreases with increasing $\mathrm{pH}$, indicating destabilization of the surface complexes. This fact contradicts stronger $\mathrm{H}$-bonding at high $\mathrm{pH}$.

3.5. Desorption of Glucose-1-phosphate from Goethite. Figure 6 shows that desorption of G1P from goethite is strongly $\mathrm{pH}$-dependent. We also observe a small dependency on the total G1P concentration at $\mathrm{pH} 5$ where desorption initially seems to be slightly faster at the higher ligand concentration. These observations can be rationalized qualitatively by analysis of the infrared spectra collected during the desorption reaction and by the proposed structures of the G1P surface complexes (Figure 5).

The infrared spectra collected at the start of each desorption experiment indicate that the initial surface speciation of G1P differs in all three experiments (Figure 7). At pH 8.5, except for an overall intensity decrease, no peak shifts or changes in relative intensities are observed during the course of the desorption process (spectra not shown). Thus, we infer that the comparatively fast desorption at $\mathrm{pH} 8.5$ (Figure 6) is due to one predominating surface complex, and according to our structural model (Figure 5) the rate is associated with the species denoted SC III. This is also the species that apart from the inner sphere coordination to $\mathrm{Fe}(\mathrm{III})$ should display the weakest additional interaction with the surface. Hence, the rate of desorption at $\mathrm{pH} 8.5$ is at least partially determined by the lability of the Fe-OPX bond. A logical consequence of this line of reasoning is that the kinetically more inert 


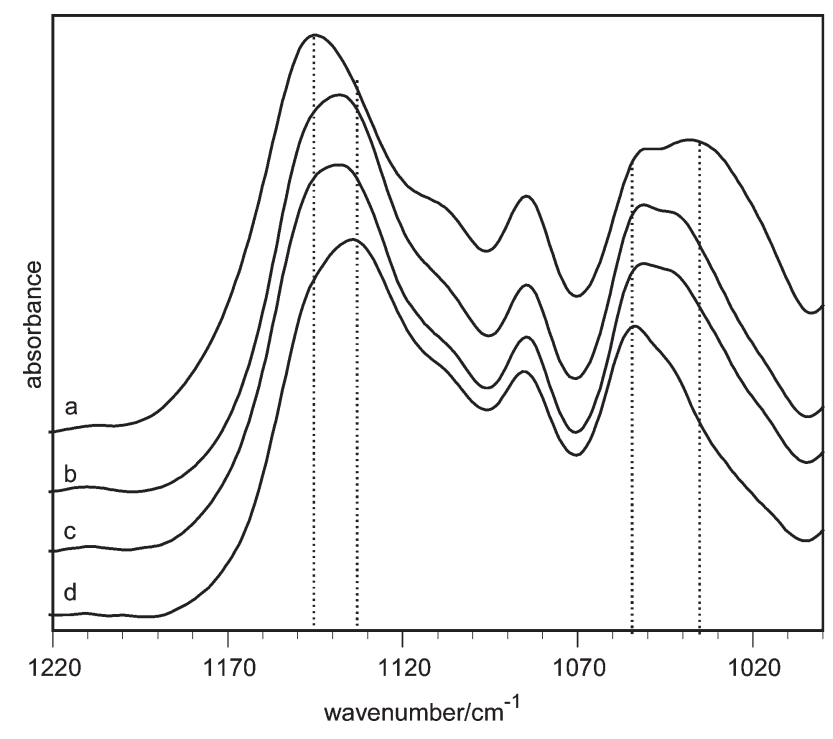

Figure 7. Data from the desorption experiments: (a) initial spectrum at $\mathrm{pH} 5.0$ and $1.36 \mu \mathrm{mol} \mathrm{G1P} / \mathrm{m}^{2}$, (b) spectrum collected after $5 \mathrm{~h}$ at $\mathrm{pH} 5.0$ and $1.36 \mu \mathrm{mol} \mathrm{G1P} / \mathrm{m}^{2}$, (c) initial spectrum at $\mathrm{pH} 5.0$ and $0.69 \mu \mathrm{mol} \mathrm{G1P} / \mathrm{m}^{2}$, and (d) initial spectrum at $\mathrm{pH} 8.5$ and $1.36 \mu \mathrm{mol} \mathrm{G} 1 \mathrm{P} / \mathrm{m}^{2}$.

character of the surface complexes predominating at $\mathrm{pH} 5$ is due to the stronger hydrogen bonding interactions via the auxiliary phosphate oxygens (Figure 5 SC I and SC II), that is, to a greater number of strong contact points between the adsorbate and the surface. However, at $\mathrm{pH}$ 5, it is also observed that differences in total G1P concentration cause changes in surface speciation as well as overall desorption behavior (Figures 6 and 7). The high G1P concentration $\left(1.36 \mu \mathrm{mol} / \mathrm{m}^{2}\right)$ results in surface species displaying the highest frequency $\mathrm{P}-\mathrm{O}$ mode but at the same time an initially slightly faster desorption as compared to the low concentration $\left(0.69 \mu \mathrm{mol} / \mathrm{m}^{2}\right)$. Furthermore, during the desorption reaction, the spectral features at $0.69 \mu \mathrm{mol} / \mathrm{m}^{2}$ do not change appreciably, whereas at $1.36 \mu \mathrm{mol} / \mathrm{m}^{2}$ the spectra initially undergo significant changes and converge toward the features at the lower concentration (Figure 7). This convergence coincides approximately with the convergence of the desorption curves after ca. $6 \mathrm{~h}$ (Figure 6). Based on the structural model presented, these results may be explained by assuming that SC I and SC II (Figure 5) predominate initially at the high and low G1P concentrations, respectively. The SC I structure, where protonated G1P is involved in strong H-bonding as a donor, is consistent with the highfrequency $\mathrm{P}-\mathrm{O}$ mode (Figure 7). Furthermore, a previous study on desorption kinetics of polycarboxylates has shown that surface complexes involving $\mathrm{H}$-bonding donor groups desorb faster than those involving $\mathrm{H}$-acceptor interactions. ${ }^{42}$ Accordingly, SC I (H-donor) should have a higher desorption rate as compared to SC II (H-acceptor), which is in agreement with the desorption results (Figure 6) given the assumed surface speciation. Hence, the desorption results corroborate the proposed structural model and the inclusion of three classes of surface complexes.

In the previous section, we qualitatively interpreted the overall $\mathrm{pH}$ - and coverage-dependent desorption rates by differences in surface speciation. In order to further study the desorption behavior of the individual G1P surface complexes, global fits using singular value decomposition (SVD) were performed. The analysis of the spectral data set of desorption at $\mathrm{pH} 8.5$ corroborated

(42) Lindegren, M. Aqueous Surface Chemistry of Goethite-Adsorption and Desorption Reactions Involving Phosphate and Carboxylic Acids. Doctoral Thesis, Umeå University, 2009. the existence of one predominating surface complex. According to the criteria accounted for in the Experimental Section, SVD predicted one significant kinetic eigenvector and a kinetic model including a simple first order decay of one species provided a reasonable fit to data (Figure 8). As expected, the calculated spectrum of the kinetic component (Figure 8) is very similar to the spectrum in Figure 7 representing the start of the desorption experiment at $\mathrm{pH} 8.5$.

At $\mathrm{pH} 5$ and $[\mathrm{G} 1 \mathrm{P}]_{\mathrm{tot}}=1.36 \mu \mathrm{mol} / \mathrm{m}^{2}$, clearly more than one surface complex contributes to the speciation (Figure 7), and consequently, the results of the global kinetic analysis of this data set is more complex. It is also clear at $\mathrm{pH} 5$ that the surface speciation depends on the total concentration of G1P (Figure 7). Thus, during desorption, the distribution of surface species is expected to change due to the preferential loss of one or several surface complexes. The SVD of the $\mathrm{pH} 5$ data set indicates three significant kinetic eigenvectors, and a three-species model with first order decay of two species together with a third species growing in at a first order rate provides a good fit to the experimental data (Figure 9) and generates calculated spectra displaying positive peaks only. These spectra are in agreement with the expected features of the proposed complexes SC I-III. Spectra (a) and (c) in Figure 9 display features in accordance with the low and high $\mathrm{pH}$ end points, as identified by the $2 \mathrm{D}$ correlation analysis (Figure 4 and Table 2). Furthermore, spectrum (c) is very similar to that of the predominating surface complex at $\mathrm{pH} 8.5$, while spectrum (a) displays characteristics similar to the spectrum collected at the start of the $\mathrm{pH} 5$ desorption experiment performed at high G1P concentration (Figure 7). In Figure 9, spectrum (b) has $\mathrm{P}-\mathrm{O}$ modes at frequencies in between those of the other two surface complexes, and according to the discussion in section 3.2 we assign this spectrum to SC II. This spectrum is also similar to the initial spectrum of the $\mathrm{pH} 5$ desorption experiment at low G1P concentration as well as after some hours of desorption at the high concentration (Figure 7), suggesting that SC II predominates under these conditions. Finally, the existence and the growth of the minor species in Figure $9 \mathrm{c}$ are corroborated by the fact that the spectra collected toward the end of the desorption experiment (not shown) are approaching the features of spectrum (c), indicating that this species indeed increases in relative importance as G1P desorbs.

The kinetic behavior of the three components, that is, the decay of two species and growth of a third, indicates that loss of a surface complex can at least have two causes: (1) desorption; (2) conversion into another surface species as properties at the interface change during desorption, for example, changes in surface charge as a result of the changing coverage. Assuming a sequential order of conversion, we can thus summarize the desorption processes as shown in Scheme 1. This demonstrates the difficulty in determining true desorption rates of individual surface complexes, and in our study only the experiment performed at $\mathrm{pH} 8.5$ is representative of the desorption rate of mainly one species. Comparison between Figures 8 and 9 shows that the loss of species a and b, i.e. SC I and II, at pH 5 is significantly slower than the desorption rate of SC III at $\mathrm{pH} 8.5$, which contradicts the observation that SC III grows in during the desorption experiment at $\mathrm{pH}$ 5. This implies that SC III desorbs at a slower rate at low $\mathrm{pH}$ and thus the rate of desorption of an individual surface complex seems to be $\mathrm{pH}$-dependent, and we hypothesize that this primarily is due to variations in surface charge. Therefore, the discussion above concerning molecular causes of the differences in desorption rates should be complemented with a factor including the surface charge. Using an 

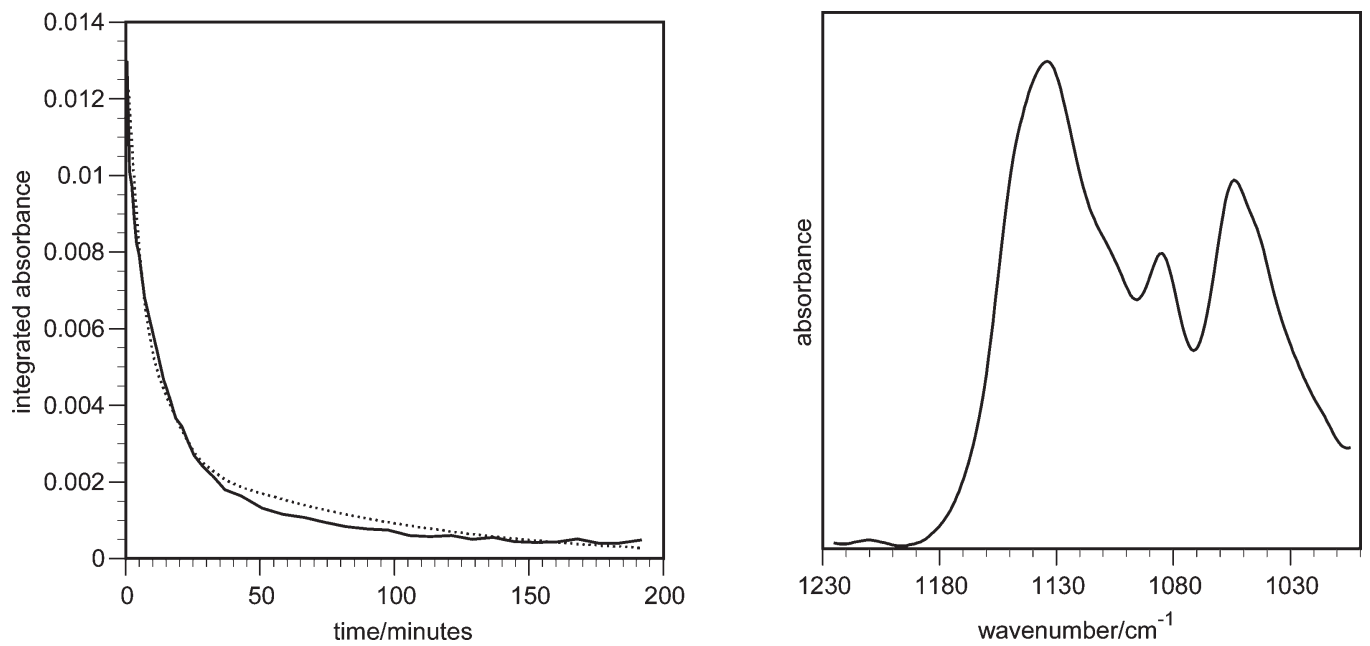

Figure 8. Left panel: Integrated absorbance between 1000 and $1230 \mathrm{~cm}^{-1}$ of G1P desorbing from goethite at pH 8.5 and $[\mathrm{G} 1 \mathrm{P}]_{\mathrm{tot}}=1.36 \mu \mathrm{mol} / \mathrm{m}^{2}$. Solid line represents the experimental data, and dotted line describes a model fit assuming first order decay of one species. Rightpanel: calculated spectrum of the kinetic component obtained from the model fit.
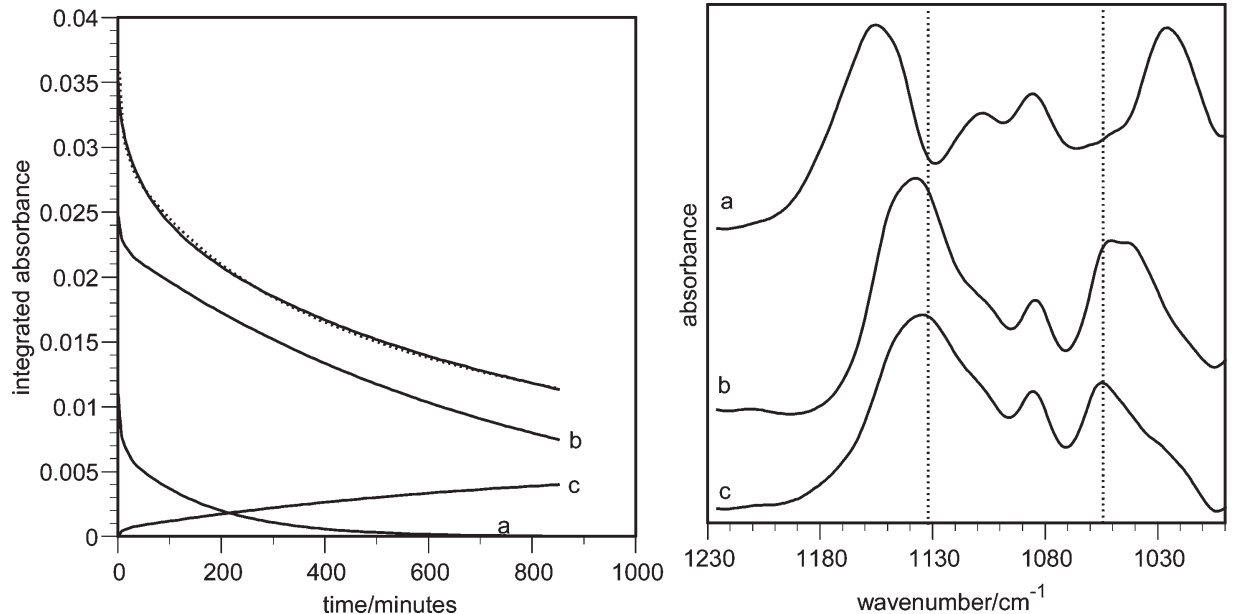

Figure 9. Left panel: Integrated absorbance between 1000 and $1230 \mathrm{~cm}^{-1}$ of G1P desorbing from goethite at $\mathrm{pH} 8.5$ and $[\mathrm{G} 1 \mathrm{P}]_{\mathrm{tot}}=1.36 \mu \mathrm{mol} / \mathrm{m}^{2}$. Solid lines represent the experimental data, and dotted line describes a model fit assuming first order decay of two species and a third species growing in at a first order rate. The predicted change of the kinetic components are denoted a, b, and c. Right panel: Calculated spectra of the kinetic components obtained from the model fit. The labels correspond to the curves in the left panel.

Scheme 1. Possible Scheme of Reactions Describing Desorption of G1P from Goethite at pH 5

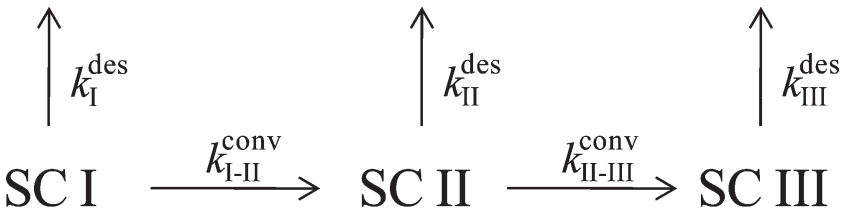

Arrhenius model, it follows that the activation energy or energy barrier that determines the desorption kinetics most probably has one intrinsic and one electrostatic factor where the former is due to molecular scale properties of the surface complex and the latter is due to the surface charge and the charge of the desorbing species. This would explain why desorption of SC III is slower at lower $\mathrm{pH}$ where the goethite surface charge is more positive.

3.6. Surface-Promoted Hydrolysis of G1P. A prerequisite to the study of the surface-promoted reaction is characterization of possible $\mathrm{pH}$-dependent hydrolysis in solution. Hence, the hydrolysis of G1P in pure ionic medium was examined by determination of the orthophosphate concentrations. In all samples, small amounts of phosphate were detected (data not shown). At lower $\mathrm{pH}$ values, the amounts increase slightly over time, indicating acid catalyzed hydrolysis of G1P. At higher $\mathrm{pH}$ and regardless of reaction time, the concentration of orthophosphate remained below $2 \mu \mathrm{M}$, and the very low and constant concentration detected may correspond to a contamination of the solid G1P used.

The extent of G1P hydrolysis promoted by goethite surfaces was determined by monitoring over time the levels of glucose in solution (Figure 10). The effects of the aforementioned acid catalyzed hydrolysis in solution are seen at $\mathrm{pH} 3$ and 4 . At higher $\mathrm{pH}$, levels of glucose increase with increasing $\mathrm{pH}$ but drop at $\mathrm{pH}$ 10. Since little or no hydrolysis was observed at $\mathrm{pH} \geq 5$ in the absence of goethite, these amounts are ascribed to surfacepromoted hydrolysis. The biotic G1P hydrolysis was assumed to be insignificant, as the glucose recovery test described in the Experimental Section showed no loss of glucose under the experimental conditions studied herein, indicating little or no microbial activity. The base-catalyzed nature of the hydrolysis is 


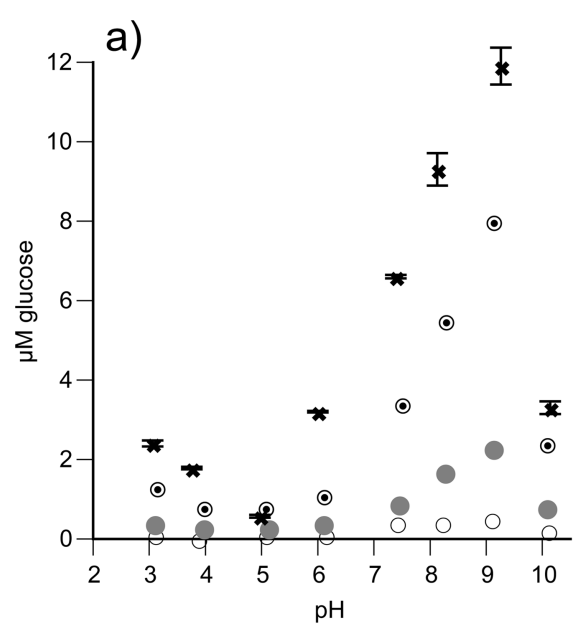

b)

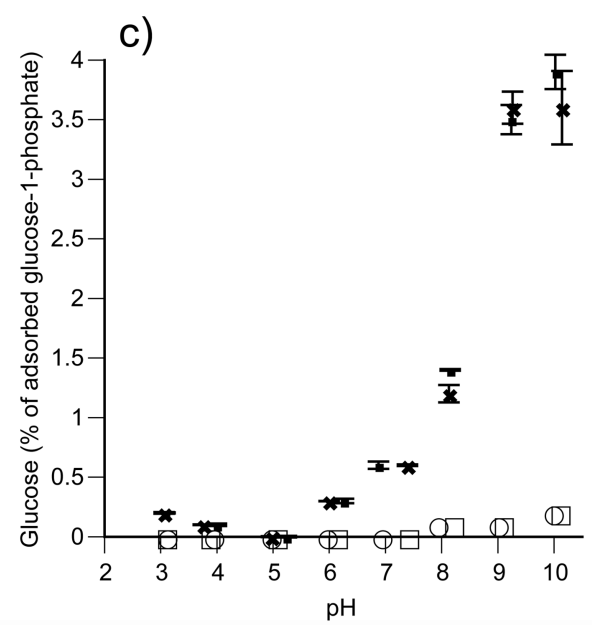

Figure 10. Glucose concentration as a function of $\mathrm{pH}$ and time, with a total $\mathrm{G} 1 \mathrm{P}$ concentration of (a) $1.38 \mu \mathrm{mol} / \mathrm{m}^{2}$ of goethite and (b) 0.69 $\mu \mathrm{mol} / \mathrm{m}^{2}$ of goethite: $(O, \square) 1 \mathrm{~h}$ samples, (solid gray circle and square) $6 \mathrm{~h}$ samples; (circle/inset circle and square/inset square) $24 \mathrm{~h}$ samples; $(\times, \boldsymbol{\square}) 48 \mathrm{~h}$ samples. (c) Glucose concentrations are normalized to the amount of G1P adsorbed. The error bars are based on the standard deviation from three individual experiments.

evident when the amounts of glucose in solution are normalized with respect to the total concentration of G1P surface complexes (Figure 10c). These normalized results also underline that the extent of surface-promoted hydrolysis is comparatively small at the experimental conditions probed in this work. Note however that small amounts of glucose may adsorb onto goethite, and consequently measurements of glucose in solution possibly will underestimate the extent of hydrolysis. Still, the general hydrolytic tendency presented is valid (i.e., increasing hydrolysis with increasing $\mathrm{pH}$ ), since glucose adsorption on goethite increases almost linearly with increasing $\mathrm{pH}^{43}$

Clearly, surface-promoted hydrolysis of G1P is most extensive in the $\mathrm{pH}$ region $9-10$ which corresponds to the region where adsorption starts when the system is titrated in the acidic direction (Figure 1). This also coincides approximately to the IEP of goethite $($ IEP $=9.4)$. Baldwin et al. ${ }^{17}$ have discussed changes in hydrolytic rate of adsorbed organophosphates and their relation to the IEP of the mineral, and noted that a hydrolytic rate maximum around the IEP is consistent with the idea of surface hydroxyl groups acting as nucleophiles in the hydrolytic process. We propose a complementary hypothesis to the surface-catalyzed hydrolysis of G1P occurring at high $\mathrm{pH}$, and we base this mainly

(43) Olsson, R.; Giesler, R.; Persson, P. Adsorption mechanisms of glucose in aqueous goethite suspensions. J. Colloid Interface Sci. 2011, 353, 263.

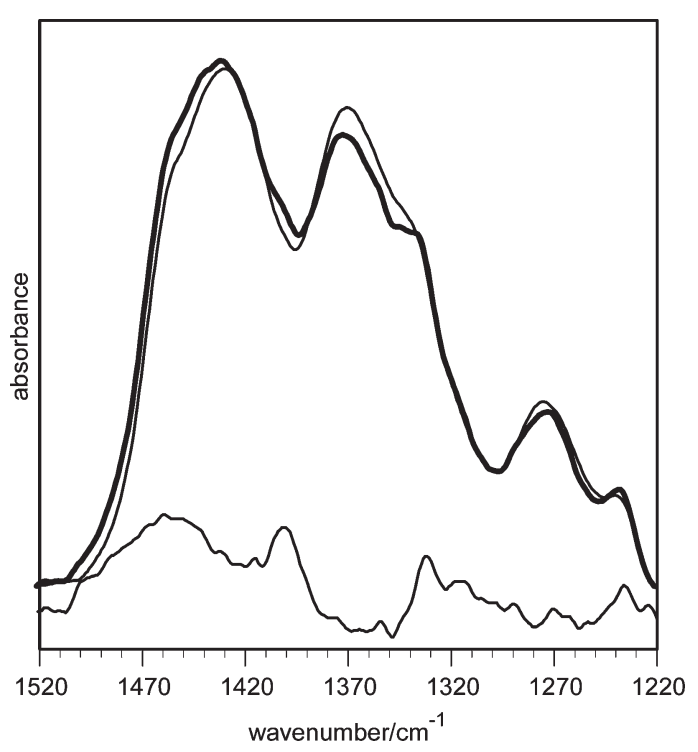

Figure 11. Infrared spectra in the $\mathrm{C}-\mathrm{O}-\mathrm{H}$ bending region of samples prepared at $1.36 \mu \mathrm{mol} \mathrm{G} 1 \mathrm{P} / \mathrm{m}^{2}$ of goethite, and pH 5.0 (thin line) and pH 8.5 (thick line). The lower spectrum of weak intensity is the difference between the $\mathrm{pH} 8.5$ and 5.0 samples. 
on the suggested structures of the surface complexes and the fact that glucose interactions with goethite are favored by basic $\mathrm{pH}$ values. ${ }^{43}$ Our idea is that SC III, which is the surface complex with weakest $\mathrm{H}$-bonding to the surface, presents the most flexible structure, and accordingly, this may be the structure best promoting interactions between the glucose moiety and the surface. These interactions can stabilize the leaving group, glucose, and hence lower the energy of the transition state in the hydrolysis reaction, thereby increasing the rate. This hypothesis is supported by observations in the region $1300-1500 \mathrm{~cm}^{-1}$ of the infrared spectra, a region which is predominated by peaks originating from $\mathrm{C}-\mathrm{O}-\mathrm{H}$ bending vibrations of glucose. ${ }^{44,45}$ As seen in Figure 11, the low and high $\mathrm{pH}$ spectra of G1P on goethite display small but detectable differences in this region, indicating different states that may arise from the proposed interactions between the glucose moiety and the goethite surface. If our hypothesis is correct, we may expect that surface promoted hydrolysis of phosphate sugars is structure specific and depends on the orientation of the leaving group with respect to surface functional groups. We are currently testing this hypothesis experimentally.

(44) Kodad, H.; Mokhlisse, R.; Davin, E.; Mille, G. Can. J. Appl. Spectrosc. 1994, 39, 107.

(45) Max, J. J.; Chapados, C. J. Phys. Chem. A 2007, 111, 2679.

\section{Conclusions}

IR spectroscopy has shown that G1P forms $\mathrm{pH}$-dependent surface complexes on goethite. The collective results from investigations of both adsorption and desorption processes are consistent with a model including three types of surface complexes. These complexes interact monodentately with surface Fe but differ in hydrogen bonding interactions via the auxiliary oxygens of the phosphate group. The apparent desorption rates have been indicated to be influenced by reaction pathways that include interconversion of surface species. This highlights the difficulty in determining the intrinsic desorption rates of individual surface complexes. Still, we may conclude that the molecular structures of surface complexes and the surface charge are two important determinants of G1P desorption rates. Finally, this study has shown that surface-promoted hydrolysis of G1P by goethite is base-catalyzed. However, the extent of hydrolysis is small and does not explain the similar behavior of G1P and orthophosphate in bioassays.

Acknowledgment. This work was supported by the Swedish Research Council. The Kempe foundation is acknowledged for providing funding of the infrared spectrometer. The molecular orbital calculations were conducted using the resources of High Performance Computing Center North (HPC2N). 